\title{
THE CHARACTER OF THE THERMAL STORAGE DEMAND METER
}

\author{
BY P. M. LINCOLN
}

Abstract of Paper

Following a detailed description of the principle and construction of the thermal storage demand meter the author shows wherein it always indicates what may be called "logarithmic average" rather than "arithmetic average" of power consumption, heretofore indicated by practically all demand meters. The inherent faults of the "arithmetic average" or "block interval" meter are described and examples given demonstrating that the thermal storage meter alone recognizes the true heating effect that fixes size of equipment and therefore cost that should be assessed against the customer.

HE ADVENT of the thermal storage wattmeter naturally raises a question concerning the character of the quantity that is measured by that device. The object of the following pages is to discuss this question and particularly to analyze the "logarithmic average"- the quantity measured by any thermal storage meter-and compare this quantity with the arithmetical average which is the quantity measured by practically all previously existing types of demand wattmeters.

Let us first consider the fundamental reasons for measuring maximum demand. Briefly stated, the incorporation of maximum demand in a rate for electric service is an attempt to assess upon the user of that service his proper share of the annual cost of the equipment necessary for giving the service. Let us assume a concrete case as an example. Assume, for instance, that the consumption of a given customer is $1000 \mathrm{kw}-\mathrm{hr}$. per year. If this load is taken at a perfectly steady rate throughout the entire year it means a steady consumption of 114 watts continuously. The amount of equipment to supply the load as thus taken is fixed by this continuous load of 114 watts. But now let us assume that our customer insists on taking his entire year's supply in a single day. Instead of equipment to supply 114 watts, we must now provide equipment to supply 41.7 
kilowatts; that is, the equipment must be 365 times as large as before. Let us go further and assume that our customer insists on having his entire year's supply in thirty minutes; this would mean an equipment able to deliver $2000 \mathrm{kw}$. for one-half hour. Obviously, the cost of the equipment for this condition would be enormously greater than that for the supply of 114 watts continuously, and it is only just that the customer that takes his entire year's supply in a day or an hour should pay more for his service than the one who distributes his demands more

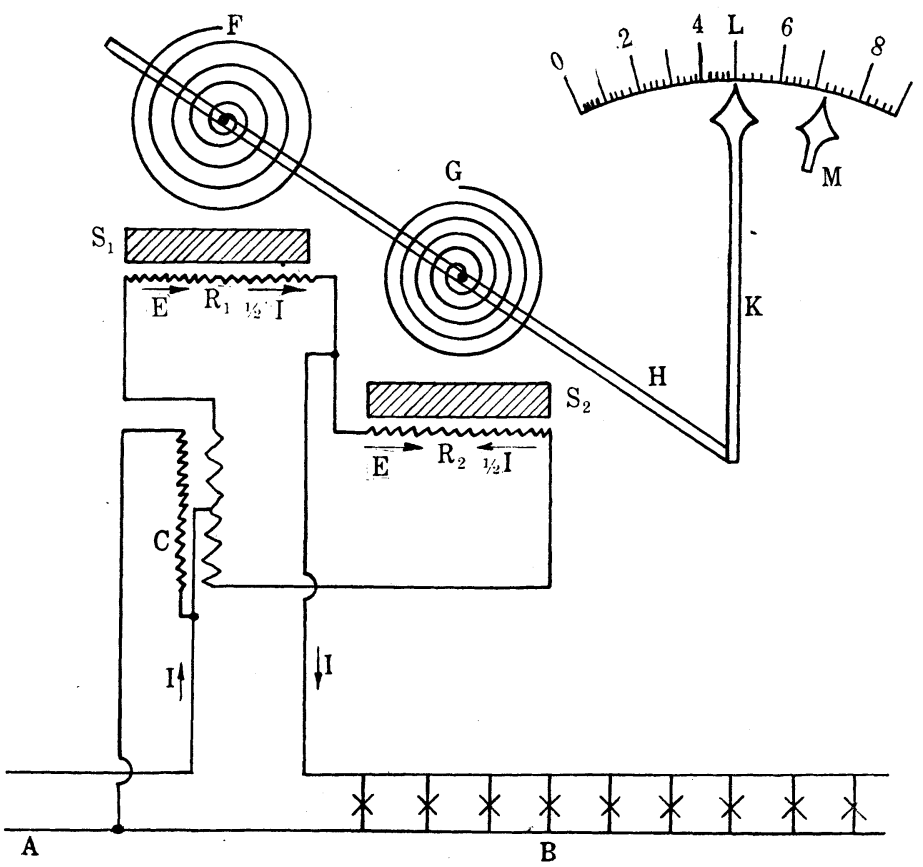

FIG. 1

evenly. Our illustration is, of course, exaggerated, but the exaggeration is one of degree and not one of kind. It is the object of the demand rate to recognize automatically this variation in the equipment necessary with variation in load factor and to assess this equipment cost against the customer. Also, it is the "maximum demand" and not the kilowatt hours of consumption that determines the amount of equipment that must be installed to carry a given customer's load. It is to determine this "maximum demand" that demand meters are used. 
It may be well at this point to give a brief description of the thermal storage wattmeter as now being built.*

Referring to Fig. 1, $A$ is a circuit feeding a load $B . \quad C$ is a small transformer incorporated within the meter with its primary across the circuit $A$. In series with the secondary of this transformer are two equal resistances $R_{1}$ and $R_{2}$. A current is, of course, set up on these resistances that is proportional to the voltage of the circuit $A$. The load current is also caused to circulate through these same resistances in the manner shown in Fig. 1, being taken into the middle of the secondary of the small transformer and being taken out at the connection between resistances $R_{1}$ and $R_{2}$. These two currents-one the secondary current, due to the presence of the voltage and the other due to the passage of the load current-are additive in one of these resistances and subtractive in the other, and the difference in the heating effect of the two resultant currents is proportional to the watts of the load $B$.

If we represent the current that passes through the resistance $R_{1}$ and $R_{2}$ due to the presence of the voltage by $E$, and the load current therein by $I$, the resultant current in one of these resistances is $E+I$, and in the other $E-I$. The losses are of course, proportional to the squares of these currents and the differences in these losses is proportional to the product $E I$. This holds true, independent of power factor and wave form, as shown in the paper above referred to.

$F$ and $G$ represent two spiral springs made from bimetallic strip, attached rigidly to their casings at the outer ends and to a common shaft $H$ at their inner ends. These bimetallic springs tend to coil up on an increase in temperature (due to the difference in temperature coefficient of the two metals of which they are composed), but, since the two springs are wound in opposite directions, no movement of the shaft $H$ will take place unless there is a difference in temperature between $F$ and $G$. The shaft $H$, therefore, will not turn with changes in atmospheric temperature or with any other condition that causes both springs to maintain the same temperature, but will respond only to the difference in temperature caused by the difference in the losses in resistances $R_{1}$ and $R_{2}$. $S_{1}$ and $S_{2}$ represent diagram-

*'The complete theory of the thermal storage wattmeter is given in the author's paper read before the American Institute of Electrical Engineers, Oct. 8, 1915, entitled "Rates and Rate Making". (TransACtions A. I. E. E. Vol. 34, pages 2175 to 2214.) 
matically the thermal storage of the cases in which the bimetallic springs $F$ and $G$ are enclosed. Due to this thermal storage, the wattmeter does not respond instantly to a change in load but always indicates the logarithmic average load over the time period immediately preceding the instant of observation, the length of this time period being determined in part by the amount of thermal storage in the cases, shown diagrammatically at. $S_{1}$ and $S_{2} . \quad K$ is a pointer attached to shaft $H$ and traveling over the scale $L . \quad M$ is a loose pointer which shows the highest excursion of pointer $K$ since last reset.

Fig. 2 is made from a photograph of a graphic meter of the thermal storage type with the cover removed, showing the working parts. The two cylindrical cases each containing a coiled bimetallic spring may be observed at the top of the instrument. The thermal storage capacity of these cases is so designed that it requires thirty minutes for them to acquire 90 per cent of their final temperature on a steady application of load. The working parts of the indicating meter is a duplicate of that shown in Fig. 2, except for the omission of clock, paper rolls, etc.

A thermal storage meter thus constructed always indicates what may logically be called the "logarithmic average" of the power consumption during the particular time period immediately preceding the instant of observation. Quoting the language of the paper above referred to on this point, the indications of a thermal storage wattmeter "will not be due to the watts passing at that instant, as is the case with the indications of an indicating wattmeter of the usual type, but will be the resultant of all the wattage flow that has passed, each instant of past flow having a value influenced in respect to its time proximity by a logarithmic law. This resultant is not an average in the commonly accepted sense of that word. When we use the word average in its commonly accepted sense, we assume that each instant of time over which the average is taken has equal weight. In the resultant that is obtained by a heat storage meter, each instant of time has not an equal weight, but the influence of each instant decreases with its remoteness in point of time, and the degree by which the watts during any instant influences the total indication is proportional to $e^{-K t}$, where $e$ is the base of Napierian logarithms, $K$ is an adjustable constant, and $t$ is the time measured backward from the instant of observation. For want of another name, let us call the resultant thus obtained by means of thermal storage the "logarithmic average." "The 
PLATE IV.

A. I. E. E.

VOL. XXXVII, 1918

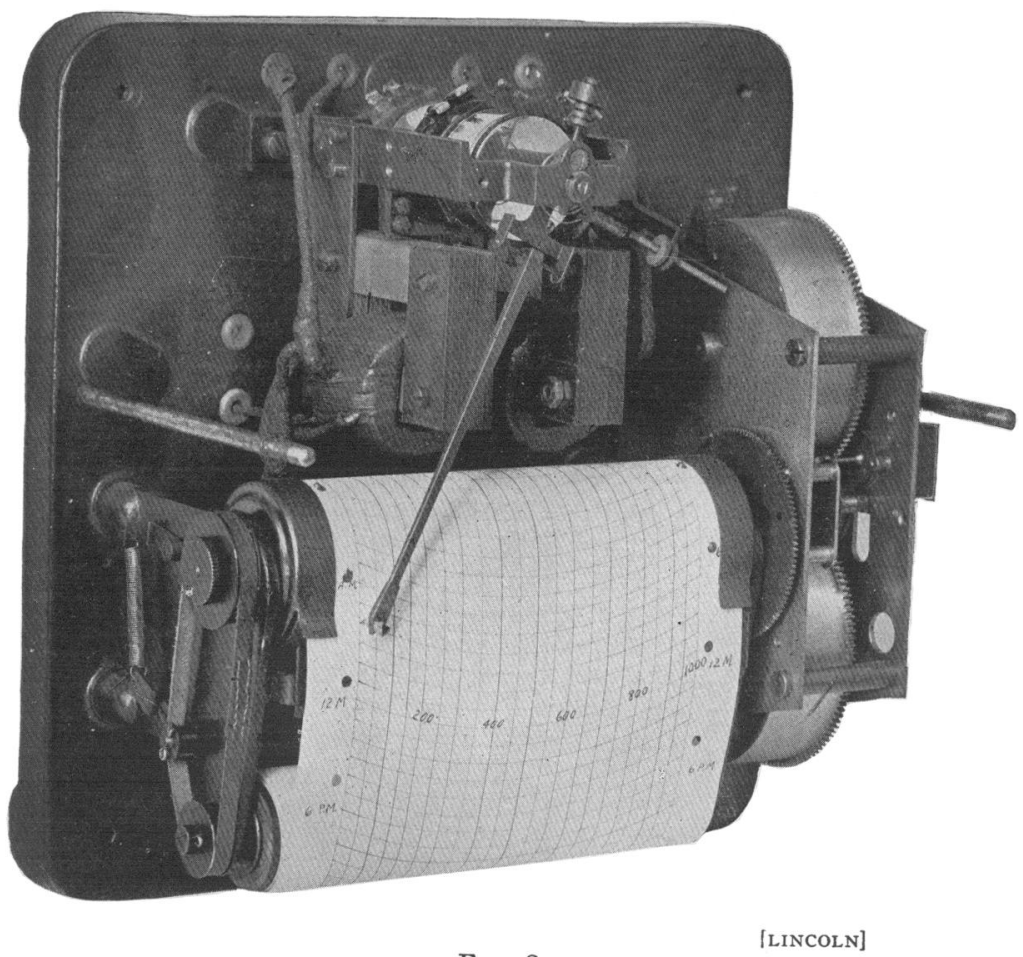

FIG. 2 
foregoing quotation indicates the nature of the quantity that is measured by the thermal storage demand meter. In a subsequent paragraph of this paper, a further quotation will be made from my previous paper showing how the "logarithmic average" of a given load may be calculated.

Heretofore, practically all demand meters have indicated in terms of the arithmetical average. This has followed from the fact that the basis of practically all previous demand meters has consisted of a standard watthour meter coupled with some timing device by means of which the integrated value of the load under measurement is obtained over a series of short time intervals. A further mechanism is provided so as to record the highest one of these successive blocks of energy. This type of meter is known as the "block interval" meter.

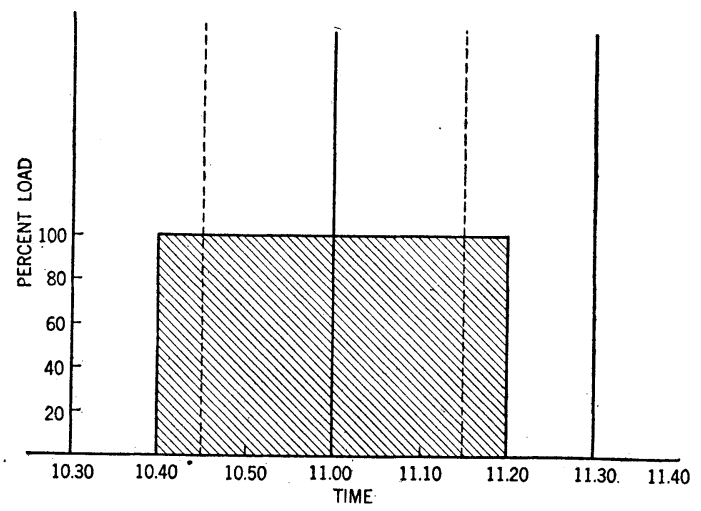

FIG. 3

One of its inherent faults is that it may split an isolated peak of load and therefore become indefinite in its indications. Reference to Fig. 3 will show the reason for this. Suppose we have an isolated block of load that comes on at say 10:40 a.m. and lasts until 11:20 a.m. - such a load for instance as would be involved in the pumping out of a small drydock. Suppose, further that we are using a "block interval" meter with a thirty minute time period to measure the maximum demand of this load. If the time intervals of this meter happened to begin and end on the even half hours-that is, if it integrated the load first from 10:30 to $11: 00$ and then from $11: 00$ to $11: 30$-it is evident that the maximum quantity indicated during any one period would be much less than if the meter periods began and ended on the even quarter hours. It is also evident by inspec- 
tion that this indefiniteness of indication begins when the duration of the block of load is less than 60 minutes and that when its duration is less than 30 minutes, this "coefficient of indefiniteness"-if we may coin that term-becomes 50 per cent; that is, a load peak of less than thirty minutes duration may be entirely integrated within a single meter period or it may be divided equally between two adjacent periods depending upon the instant of time when these meter periods begin and end. There have been various suggestions of methods to overcome this fault but so far none of these suggestions has borne fruit.

A second and more serious fault of the "block interval" meter is that for isolated blocks of load it does not measure the

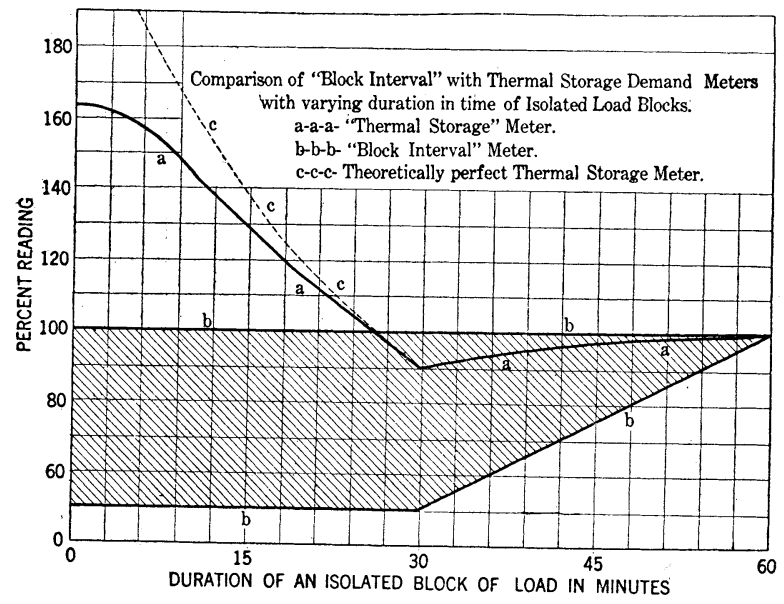

FIG. 4

true value of its heating effect on the equipment that serves the load and therefore does not measure the true value of the duty on that equipment. This matter is further treated in subsequent paragraphs. There has been no suggestion of any method by which the "block interval" meter may overcome this fault and there seems to be no possibility of such a suggestion.

So long as the loads are steady over long periods of time, the arithmetical (block interval) and the logarithmic (thermal storage) averages are exactly the same. It is only when the duration in time of a block of load begins to come down to the time period of the meter that there is an appreciable difference between the two types. To assume a concrete case again, suppose that service is being sold on the basis of the maximum 
demand over a 30 -minute period. So long as the duration of an isolated block of load exceeds one hour (twice the meter period) the "block interval" and thermal storage meters will give the same results for all practical purposes. Theoretically, for periods of load duration greater than twice the meter period (sixty minutes in our concrete case) the difference between the two types is less than one per cent. For load duration less than 60 minutes, the comparison between the two types of meter is shown in Fig. 4.

The cross hatched area in Fig. 4 indicates what may be called the "area of indefiniteness" of a "block interval" meter of 30minutes time period; for isolated blocks of load of less than 60 minutes duration, the indications of the "block interval" meter may fall anywhere within this area. On the other hand, the thermal storage meter is perfectly definite in its indication. Each time a given load of given time duration is applied to this type of meter, it gives the same indication.

However, this indication differs from that of the "block interval" meter and the comparison between the two types is given in curve $A A A$ in Fig. 4. For a 60-minute block of load, there is a difference between the two types of only one per cent. As the block continues to decrease in time of duration, the thermal storage meter continues to decrease in indication compared to the "block interval" meter (assuming that the "block interval" meter is reading its maximum) until with a 30 -minute block of load it reaches 90 per cent. As the time of load duration continues to decrease below 30 minutes, the indications of the thermal storage meter increase until with very short applications of load it indicates about 163 per cent of the maximum of the "block interval" meter and 326 per cent of its minimum.

There will be some one who will at first be constrained to comment adversely on the fact that the thermal storage meter reads higher than the "block interval" meter for all load durations less than about 26 minutes, and that when the load durations are very short, this discrepancy is so large. The action of the thermal storage meter in this respect is, however, entirely defensible. Referring, for instance, to the same concrete example we used above, suppose our customer with a yearly consumption of 1000 $\mathrm{kw}$-hr. insists on taking his entire year's supply in one minute. $\mathrm{He}$ would obviously use energy during this one minute at the rate of $60,000 \mathrm{kw}$. Electrical equipment can, of course, be grossly overloaded for so short a time as one minute, but even 
with the greatest overload imaginable, the amount of equipment to carry $60,000 \mathrm{kw}$. for one minute is more than that to carry $2000 \mathrm{kw}$. for 30 minutes. The "block interval" meter would recognize no difference whatever between these two conditions, since the arithmetical average of the two loads when taken over a 30 -minute period is exactly the same. The thermal storage meter, however, discriminates automatically against the shorttime high-peak load and gives a result which in any event follows the same kind of a law as does the heating of the equipment that

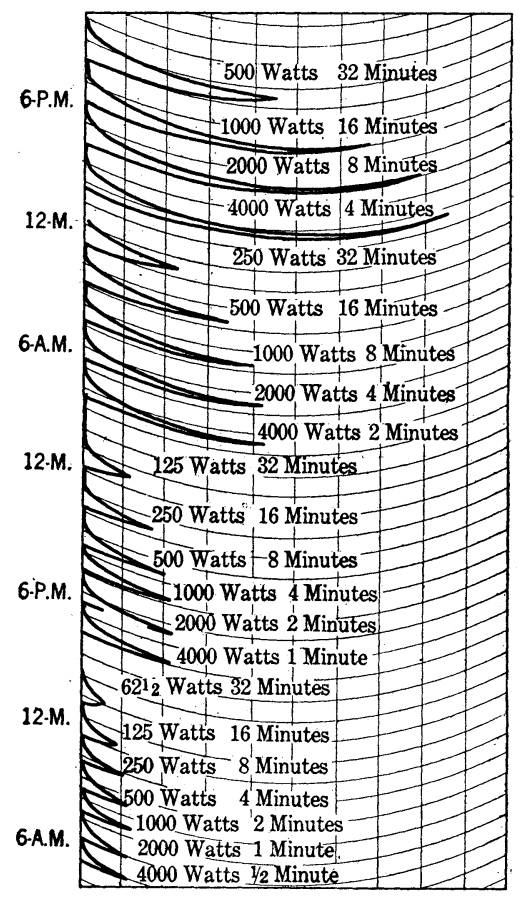

FIG. 5

furnishes the power. In short, both the "block interval" and the thermal storage meters recognize the effect of load factor so long as the duration of the block of load is equal to or greater than the meter period. However, when the load duration is less than the meter period, the "block interval" meter recognizes no difference while the thermal storage meter continues to recognize the heating effect of a given block of load entirely independent of its duration in time. It is the heating effect that fixes the size of the equipment, and, therefore, the cost 
that should be assessed against the customer. It follows, therefore, that the indications of the thermal storage meter are more logical for rate making purposes than are those of the arithmetical average or "block interval" meter.

In this connection, the results of tests shown in Figs. 5, 6, 7, 8 and 9 will be of interest. These show the results of a number of test runs made with a graphic meter of the thermal storage type. These tests were made on the instrument shown in Fig. 2. The time period was 30 minutes; that is, the application of a steady load would bring the meter indication to 90 per cent of final at the end of 30 minutes, 99 per cent at the end of 60 minutes, 99.9 per cent at the end of 90 minutes, etc. The paper speed was one-quarter inch per hour and the full scale was 1000 watts. Fig. 5 shows the result of four series of tests. In the first series shown at the right hand bottom of Fig. 5, 2000 watt-minutes were applied to the meter, each test of the series starting at zero. In the first test of the first series the whole 2000 watt-minutes were put in in one-half minute; that is, power was applied at the rate of 4000 watts (four times normal load) for one-half minute. After the meter had had time to return to zero, the second test of the series was applied, viz., 2000 watts for one minute. The third block was 1000 watts for two minutes; then follow 500 watts for four minutes, 250 watts for eight minutes, 125 watts for 16 minutes and 62.5 watts for 32 minutes. If these same tests had been applied to a "block interval" meter they would all have given the same results (barring the "indefiniteness" mentioned in a preceding paragraph) if measured on a 30minute meter except, of course, the last test of the series, which would have been lower than the others in the ratio of 30 to 32 . I think there are very few who will contend that the customer who insists on taking his entire half hour's requirements in a half minute should not pay a larger demand rate than the one who spreads it out evenly throughout the half hour.

The second series of tests, shown in Fig. 5, is the same as the first except. that the amount of power is doubled, 4000 wattminutes being applied instead of 2000 . No tests were made that involved applying load at a rate greater than four times normal. Similarly, in the third and fourth series of tests, 8000 and 16,000 watt-minutes were applied respectively, with the results shown. Comparing the four series of tests with each other, it will be seen that doubling the watts for a given time period doubles the meter indications, as, of course, might have been anticipated. 
Comparing now the individual tests of a given series and comparing these results with those deduced from purely theoretical considerations, we find that the quantity indicated by the actual

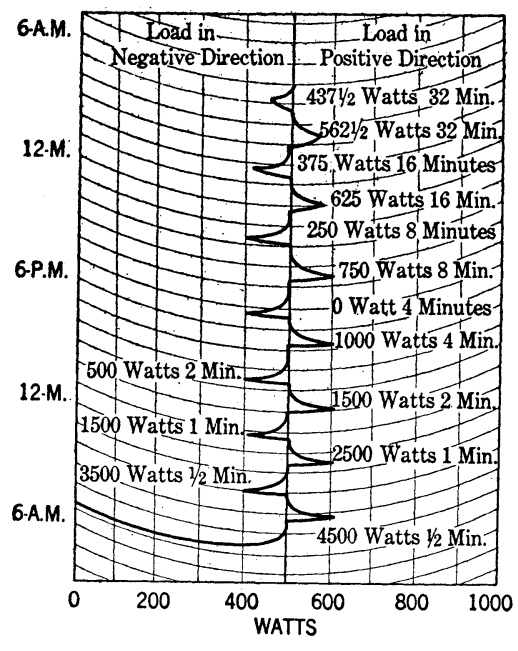

FIG. 6

meter when subjected to isolated short time blocks of load is not as great as the true logarithmic average. Referring to Fig. 4, for instance, the curve $A A A$ and the area $B B B$ compare the

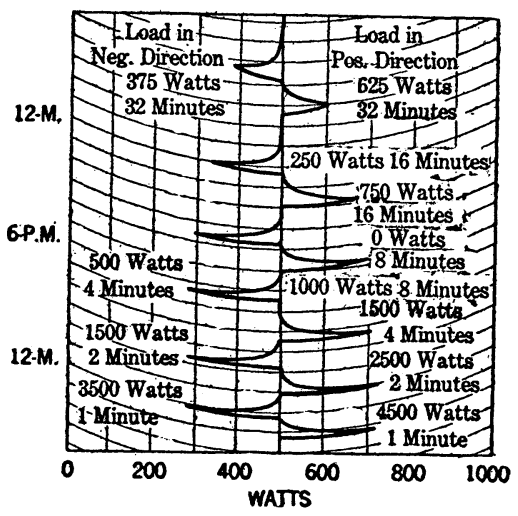

FIG. 7

actual thermal meter with the equivalent "block interval" meter. If the thermal meter had followed a true logarithmic law, the comparison would have been shown by the dotted curve $C C C$ 
instead of the solid curve $A A A$. The reason for this and a discussion thereof will be set forth in a later paragraph of this paper.

Figs. 6,7 and 8 are identical with Fig. 5 insofar as the value of the load fluctuation is concerned, but the fluctuation is made with the meter starting from and returning to the half load point instead of the zero load point. In Fig. 6, for instance, there is shown a series of tests that are taken with the application of the following schedule. The meter was operated at 500 watts for a long enough period for the pen to take up the 500 watt position; then, 4500 watts was applied in a positive direction for one-half minute and the load was returned there-

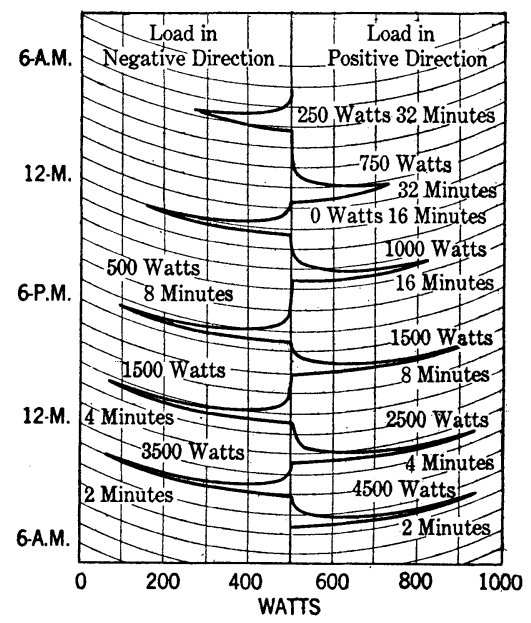

FIG. 8

upon to this 500-watt point. After the return of the pen to the steady 500 -watt position, 3500 watts was applied to the meter in a negative direction for one-half minute, the load then being returned to the 500 watt point. This caused the pen to travel in a negative direction by the same amount as the first application caused it to travel in the positive direction. Also, it will be noted that the travel of the pen in both these tests is the same as in the first test of the first series in Fig. 5. The remainder of the tests in Fig. 6 are according to the following schedule, it being understood that after the application of the scheduled load, the load was in each case returned to the 500watt point: 


\begin{tabular}{|c|c|c|c|c|c|c|c|}
\hline $\begin{array}{l}2500 \\
1500\end{array}$ & " & “ & “ & negative & “" & " 1 & ، \\
\hline 1500 & “" & “ & “ & positive & “" & \multicolumn{2}{|c|}{2 minutes } \\
\hline 500 & “" & “" & “" & negative & “ & “ & “ \\
\hline 1000 & “" & “" & "، & positive & "، & “ & “ \\
\hline 0 & “ & “ & “" & & & “ & “" \\
\hline 750 & “" & “ & “ & positive & “" & “ & “" \\
\hline 250 & “ & “ & “" & " & “ & " & $"$ " \\
\hline 625 & “ & “ & “ & “" & “ & “ 16 & “ \\
\hline 375 & “ & “ & " & “" & “ & “ 16 & “ \\
\hline 562.5 & “ & “ & “" & “ & “ & “ 32 & “ \\
\hline 437.5 & “" & “ & “ & “، & “ & " 32 & " \\
\hline
\end{tabular}

In other words, this schedule is a repetition of that shown in Fig. 5, except that it goes both ways from the 500-watt point instead of only one way from the zero point. A comparison of the various readings indicates that a given departure in load from the 500-watt point gives exactly the same result as the same degree of departure from the zero point-a result that might have been expected.

Figs. 7 and 8 show the same thing as Fig. 6 except that the loads are respectively twice and four times those in Fig. 6. These results may be compared directly with those in Fig. 5. Fig. 9 shows the result of a load schedule exactly similar to Fig. 5 except that the point of departure is made the full-load or 1000-watt point instead of the zero point as in Fig. 5 , or the 500-watt point as in Figs. 6, 7 and 8. Figs. 5, 6, 7, 8 and 9 indicate that a given departure for a given time from the previous steady condition always gives the same result independent of where that previous steady condition has maintained the pen.

In the foregoing tests are given the results of applying isolated blocks of load to the thermal storage meter. The question now naturally arises, suppose the blocks of load are not isolated, but follow each other before the meter has had time to return to zero. The series of tests shown in Figs. 10, 11, 12, 13 and 14 were undertaken to answer this question. Fig. 10, for instance, shows three series of tests. In the first series, (shown at the right hand side of Fig. 10) 1000 watts were put on the meter and kept on for one minute; the load was then thrown completely off for one minute, that is, the time cycle was two minutes long. Both the load and the time of application were then accurately kept on a repetition of this load schedule for about one and a half hours. It will be noted that the meter pen came to a steady value of 500 watts just as if a steady load of 500 watts were 
applied instead of a full load and zero load during alternat minutes. The second series of tests shown in Fig. 10 is exactly similar to the first, except in point of time of power on and power off, being a two-minute interval instead of one minute; that is, the time cycle was four minutes long. In the third series, the time cycle of load on and load off is ten minutes long, five minutes on and five off. Referring now to Fig. 11, which is a continuation of Fig. 10, this shows three similar series of tests, the difference being that the time cycles are 20

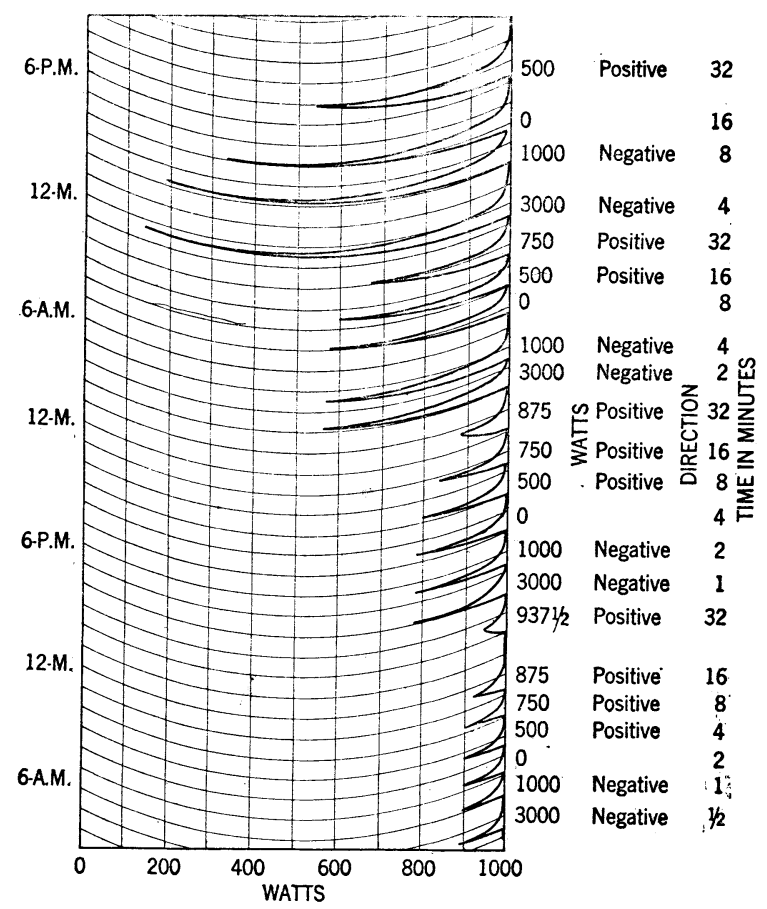

FIG. 9

minutes, 30 minutes and 60 minutes, respectively. In each of these power schedules, the average use of power is of course, at the rate of 500 watts. With the two-minute cycle the successive blocks of power blend into each other so that the result is the same as if 500 watts were applied continuously. When time of the cycle is increased to four minutes, the pen responds slightly to successive blocks of load application; the total travel of the pen being perhaps two per cent of the total scale. When the time of the cycle becomes ten minutes, this travel increases to 
about ten per cent of total scale. With a 20 -minute cycle, this travel becomes about 25 per cent; with a 30 minute cycle about 45 per cent and with a sixty minute cycle, 80 per cent. If we compare the thermal storage meter with the "block interval" meter for these various load conditions, we will note the rather curious fact that for certain time intervals, the "block interval" meter has an "area of indefiniteness," while for others it has not. Figs. 12, 13 and 14 show a number of series of tests on power

TABLE I.

\begin{tabular}{|c|c|c|c|c|}
\hline \multirow{3}{*}{$\begin{array}{l}\text { Duration } \\
\text { of cycle } \\
\text { minutes }\end{array}$} & \multirow{3}{*}{$\begin{array}{l}\text { Per cent of } \\
\text { time of } \\
\text { power on }\end{array}$} & \multicolumn{3}{|c|}{ Meter indications. } \\
\hline & & \multirow[b]{2}{*}{ Logarithmic } & \multicolumn{2}{|c|}{ Block interval } \\
\hline & & & Maximum & Minimum \\
\hline 2 & 0.25 & 250 & 250 & 250 \\
\hline 2 & 0.50 & 500 & 500 & 500 \\
\hline 2 & 0.75 & 750 & 750 & 750 \\
\hline 4 & 0.25 & 260 & 267 & 250 \\
\hline 4 & 0.50 & 510 & 533 & 500 \\
\hline 4 & 0.75 & 755 & 767 & 750 \\
\hline 10 & 0.25 & 285 & 250 & 250 \\
\hline 10 & 0.50 & 550 & 500 & 500 \\
\hline 10 & 0.75 & 800 & 750 & 750 \\
\hline 20 & 0.25 & 360 & 333 & 250 \\
\hline 20 & 0.50 & 640 & 667 & 500 \\
\hline 20 & 0.75 & 855 & 833 & 750 \\
\hline 30 & 0.25 & 425 & 250 & 250 \\
\hline 30 & 0.50 & 725 & 500 & 500 \\
\hline 30 & 0.75 & 890 & 750 & 750 \\
\hline 60 & 0.25 & 640 & 500 & 250 \\
\hline 60 & 0.50 & 900 & 1000 & 500 \\
\hline 60 & 0.75 & 980 & 1000 & 750 \\
\hline
\end{tabular}

cycles of the same length as in Figs. 10 and 11-viz., the cycles are of two minutes, four minutes, 10 minutes, 20 minutes, 30 minutes and 60 minutes. However, in Figs. 12, 13 and 14, the power is kept on during one-fourth and three-fourths of the time instead of one-half of the time as in Figs. 10 and 11. The resulting pen traces are highly interesting and instructive. Tabulating all of these results we arrive at the comparison between the two types given in Table I. 
The two minute, ten minute and thirty minute cycles all give an arithmetical average of 250,500 or 750 watts as the case may be, independent of the point in the cycle where the meter period begins. The other time intervals vary over the limits assigned in Table I, depending on what point in the power cycle the meter period begins.

It is evident from an inspection of Figs. 10, 11, 12, 13 and 14 as well as the foregoing table that the values indicated by the thermal storage meter increase in a definite, logical and consistent manner as the time period between peaks is increased

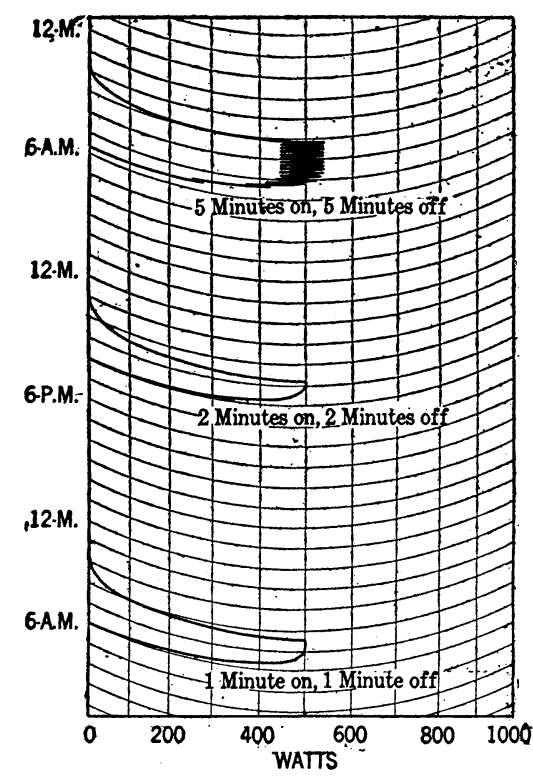

FIG. 10

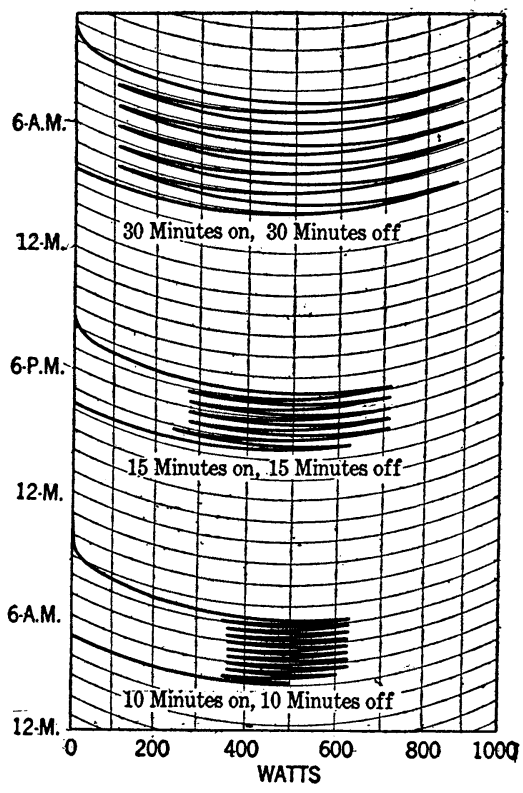

FIG. 11

while the "block interval" meter gives results that are indefinite, illogical and inconsistent under the same conditions. In other words, the thermal storage meter recognizes the maximum heating effect of a given load application of any character, while the "block interval"- meter does not.

It may be of interest at this point to make a brief analysis of the action of the thermal demand meter and show the reasons for its departure from indicating a true logarithmic average for isolated short time loads as was referred to in a previous paragraph. Fig. 15 is a reproduction of Fig. 6 taken from the au- 
thor's A. I. E. E. paper of October 8, 1915, and referred to in a previous paragraph. This shows how the "logarithmic average" of a given load may be calculated from purely theoretical considerations. Quoting from that paper, page 2195: "Suppose we have a load constantly varying with time as indicated by the broken line $C H D E I K F M$. If we apply a thermal storage meter to this load of such characteristics that it requires an hour for it to attain 90 per cent of its final indication, the cooling (or heating) curve of that meter will follow the law indicated by curve $A$. The quantity that will be indicated by such a thermal storage meter at any given instant (for instance, at 12 o'clock in Fig. 6), will be proportional to the cross-hatched

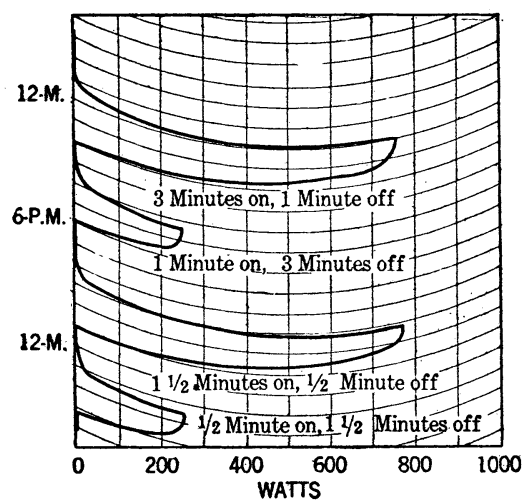

FIG. 12

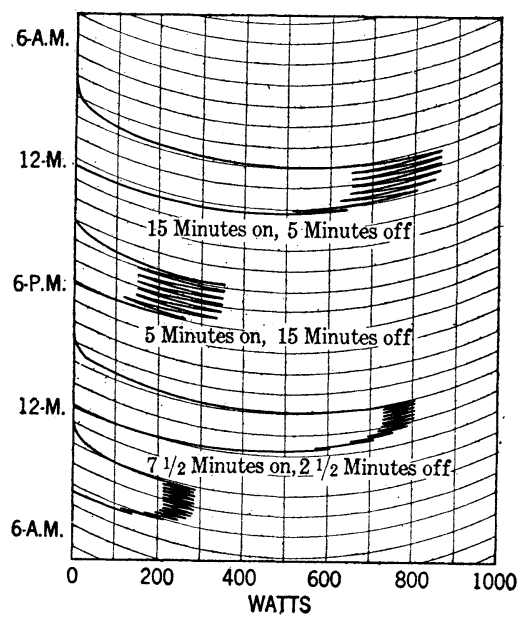

FIG. 13

area under the broken line $C^{\prime} H^{\prime} D^{\prime} E^{\prime} I^{\prime} K^{\prime} F^{\prime} M^{\prime}$. The value of the ordinates of this cross-hatched area at any instant are proportional to the value of the power ordinate at that instant reduced by the ratio of the ordinate of curve $A$ at that instant to the maximum ordinate $O G$ of curve $A$. If we can just imagine this curve $A$ as continually sliding along the power curve, the quantity which it measures will always be proportional to an area that is secured at each instant, just as Fig. 6 shows it at the instant of 12 o'clock.

"If our meter is a ten-minute meter instead of one-hour meter-that is, if it takes only ten minutes to cool down or heat up to within 10 per cent of its final value-the quantity that will be measured will be proportional to the cross-hatched 
area under the broken line $K^{\prime \prime} F^{\prime \prime} M^{\prime \prime}$. In this case, the ordinates of this area are reduced in accordance with the logarithmic curve $B$ instead of $A$; the curve $B$ comes down to 10 per cent of its initial value in ten minutes instead of one hour as is the case of $A$."

The above shows the method of calculating the indications of a theoretically perfect thermal storage meter. For short time applications of load, however, the actual meter is not theoretically perfect. The principal cause for this departure is the fact that diffusion of heat throughtout the mass of a meter

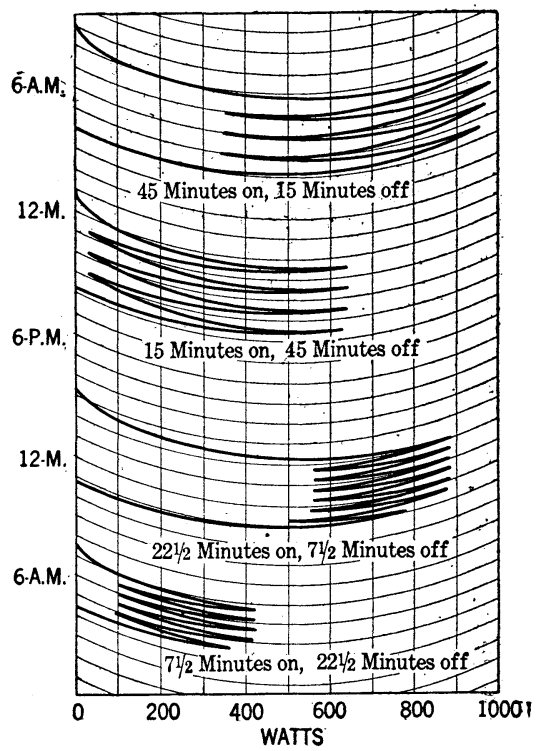

FIG. 14

element is not instantaneous. Consider, for instance, the application of a one-minute load to such a meter. Test shows that it takes nearly five minutes after the load is thrown off before the pointer reaches its maximum position. The application of this isolated block of load heats one meter element and cools the other from the previous steady condition. This wave of heat change, of course, originates in the resistance, but to effect the meter must pass to the spiral bimetallic springs. That is, the heat must first pass from the resistances to the casings enclosing the springs, then the air inside the casings is heated and this, in turn, heats the bimetallic springs. The heat must get 
from the resistances to the bimetallic springs before the meter will respond. This process takes time. During this time some heat that has been put into the resistance escapes from the casing partly by radiation and convection and partly by conduction back through the lead wires. This action leads to no departure from theoretical when the load is steady but only when the load is an isolated block. The amount of this departure can readily be found from the results of the tests shown in Figs. 5, 6, 7, 8 and 9 and the comparison of the actual meter with the theoretically perfect meter is shown by comparing the solid and dotted lines in Fig. 4. This comparison is also shown directly in Fig. 16. It might be noted that such departure as

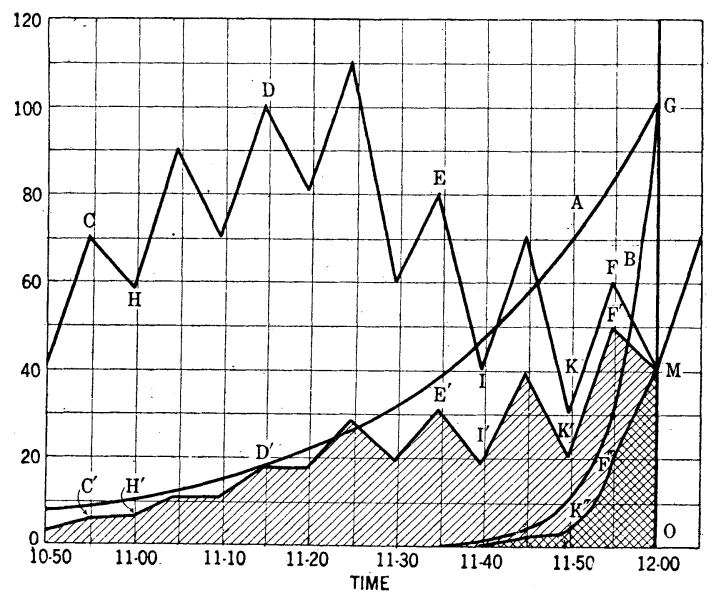

FIG. 15

there is from the theoretically perfect meter causes the actual meter to read lower than the theoretical. This is the "safe" position. If any device used in determining a customer's bill, favors the company supplying the service, it can be successfully attacked by the customer. If the contrary is true, it cannot. Hence, the departure noted is on the "safe" direction.

An objection has been raised to the thermal storage meter in that it reads higher on an increasing load than it does on a decreasing load, the ki.owatt hours and the time of appication being the same in both cases. The tests shown in Fig. 17 were undertaken to find the value of this discrepancy. In this figure, the first test (beginning at the right hand side) was made by applying 10 per cent load during the first minute, 20 per cent 
during the second minute, 30 per cent during the third, etc., until ten periods of one minute each had been applied, the last one minute period being 100 per cent load. In the second test, exactly

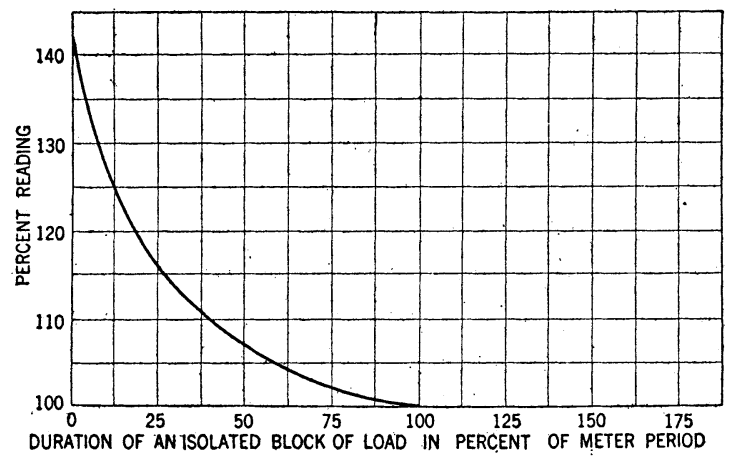

Fig. 16-Theoretically Perfect Thermal Meter Compared to Actual Performance

the same load schedule was applied, except that the time of each application was made for two minutes instead of one. In the third test, this time period was increased to five minutes. In

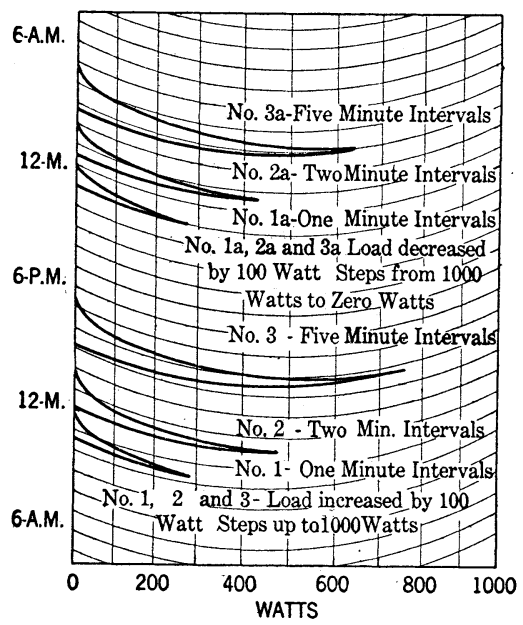

FIG. 17

the next series of tests, the load was made to decrease with time instead of increase; during the first time interval, 100 per cent load was applied, followed during the next interval by 90 per cent load, then 80 per cent, etc., until during the tenth interval 10 
per cent load was applied. The time intervals were one minute, two minutes and five minutes as in the first series. The comparison of the actual thermal meter, the theoretically perfect logarithmic average meter and the arithmetical average meter for these various load applications is given in the following table. (Percentage is variation from perfect logarithmic meter.)

\begin{tabular}{|c|l|l|l|l|l|}
\hline $\begin{array}{c}\text { Time } \\
\text { interval. } \\
\text { Minutes }\end{array}$ & $\begin{array}{c}\text { Nature } \\
\text { of } \\
\text { load }\end{array}$ & $\begin{array}{c}\text { Actual } \\
\text { meter }\end{array}$ & $\begin{array}{c}\text { Theoretically } \\
\text { perfect } \\
\text { meter }\end{array}$ & \multicolumn{2}{|c|}{ Block interval meter } \\
\cline { 3 - 5 } & & & & Maximum & Minimum \\
\hline 1 & Increasing & $295(10.2 \%)$ & 328 & $187(43 \%)$ & $93(71.5 \%)$ \\
1 & Decreasing & $275(1.8 \%)$ & 280 & $187(33.3 \%)$ & $93(66.7 \%)$ \\
2 & Increasing & $480(9.4 \%)$ & 529 & $373(29.5 \%)$ & $187(64.7 \%)$ \\
2 & Decreasing & $425(0 \%)$ & 425 & $373(12.3 \%)$ & $187(56 \%)$ \\
5 & Increasing & $760(4 \%)$ & 792 & $750(5.2 \%)$ & $450(43.2 \%)$ \\
5 & Decreasing & $630(0.2 \%)$ & 631 & $750(9.6 \%)$ & $450(28.8 \%)$ \\
\hline
\end{tabular}

The reason for the difference in indication between increasing and decreasing loads is readily seen by reference to Figs. 18, 19 and 20. In Fig. 18 the method of analysis shown in Fig. 15 is applied to a load increasing by 10 per cent steps. The reading of a theoretically perfect meter on such a load would be proportional to the cross-hatched area in this figure. Fig. 19 shows the same method of analysis applied to a decreasing load. The cross-hatched area in this figure is obviously less than that in Fig. 18. However, the instant chosen in Fig. 19 is not the instant of maximum indication. The instant of maximum indication with a decreasing load occurs before the entire block of load has passed through the meter. The instant shown in Fig. 20 gives a considerably larger cross-hatched area than that in Fig. 19. In other words, with a decreasing load, the maximum indication arrives before the whole load has been put in. Or, to put it in another way, with an increasing load, each increment of load finds the meter already heated by the preceding load and the maximum load is applied to the hottest meter element. With a decreasing load, the maximum load is applied to the coldest meter condition and the maximum temperature arrived at is not as great as with an increasing load. This action is entirely defensible since exactly the same action takes place in the equipment that serves the load. An increasing load heats up transformers, cables, generators, etc., more than does a 
decreasing load, although the kilowatt-hours and the time of application are exactly the same in each case.

The question may properly be raised as to the proper time period to use in the measurement of maximum demand. At present, the practise of various public service companies varies in this respect over a very large range. One minute is the minimum time duration for maximum demand measurement that the author is aware of and one hour is the maximum. Between

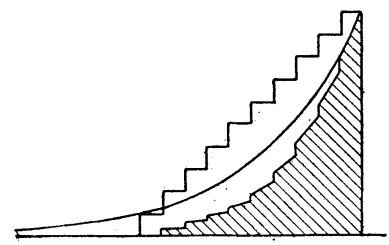

FIG. 18

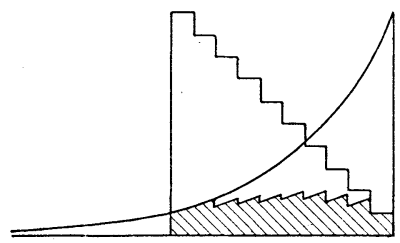

Frg. 19

these limits a large number of time periods have been proposed and used. So long as it is recognized that equipment cost is the element that dictates the maximum demand portion of a customer's bill, the use of time periods of less than about thirty minutes cannot be justified, since no part of a normal equipment for supplying electric service to a customer has heat storage characteristics that will cause it to arrive at 90 per cent of its final temperature in less than thirty minutes and many of the items of such

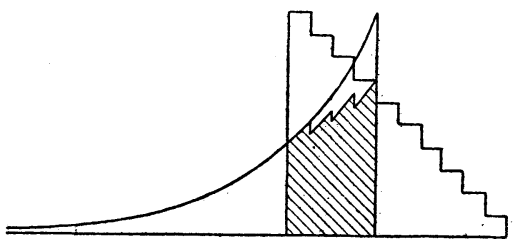

FIG. 20

an equipment have a much longer time period. In many cases, short-time periods for maximum demand have been adopted for the purpose of penalizing the customer with a high short-time peak. The thermal demand meter does this automatically and, therefore, there is not the same reason for using short periods when measuring demands with a thermal meter that there is when using the "block interval" meter. For steady loads, it does not matter whether the demand is on a one minute or a 
one hour basis, the result is the same. The average generator, transformer or cable has heat storage characteristics that usually require a time considerably in excess of 30 minutes for them to arrive at 90 per cent of their final temperature when a steady load is applied. A 30-minute meter, therefore, is about the minimum time period for maximum demand that can be justified on the score of assessing equipment costs against the customer and the tendency of the future will undoubtedly be toward longer time periods. The 30-minute thermal demand wattmeter is the first time period to be developed but other time periods will be brought out as occasion requires.

\section{SUMMARY}

1. The cost of electric service is dependent in part upon the cost of the equipment necessary to provide that service.

2. The cost of the necessary equipment to a given customer depends upon his maximum demand and not on his kilowatthours of consumption.

3. The thermal storage demand meter gives a perfectly definite indication independent of the character of the load applied, while the "block interval" demand meter becomes highly indefinite on short-time peak-load applications.

4. For short-time peak-load applications the thermal storage demand meter follows a law of the same nature as the heating effect of the load application upon the service equipment, while the "block interval" meter does not.

5. For steady loads the thermal storage and "block interval" demand meters give identical results.

6. The thermal storage demand meter gives a much higher indication for a very short-time peak-load application than does the "block interval" demand meter, thereby making unnecessary the adoption of short demand periods designed to penalize such high peak loads. 


\section{Discussion on "The Character of the Thermal Storage} Demand Meter." (Lincoln), New York, February 15, 1918.

C. I. Hall: A very large part of the justification for the use of a thermal type of demand meter is based upon the idea that the primary rate should be proportioned to the thermal capacity of the equipment required to serve a customer. Since the thermal capacity of the various units of the installation depends very largely, or entirely, upon the current flowing rather than the wattage of the circuit, would it not be very much more logical to employ a thermal ammeter for such measurements than a thermal wattmeter?

It is very interesting to note the modification of the characteristic curve of the thermal storage wattmeter as compared with the curve indicated in Mr. Lincoln's paper on "Rates and Rate Making" of October, 1915. At that time in the discussion there was presented a curve on the characteristics of three different types of demand meters, the first being the Wright demand, the second the logarithmic average as taken from Mr. Lincoln's paper, and the third the characteristic of a thermal ammeter.

The approach of the Lincoln thermal demand meter described at that time to the theoretical logarithmic curve was very close on account of the very rapid dissipation of heat throughout the measuring apparatus.

In connection with the modifications which have been made by the use of a bi-metallic strip where the heat, which is proportional to the wattage, is applied to one end, the deviation from the theoretical logarithmic curve is considerably greater, and by taking the curves as presented in the present paper, it is interesting to note that the curve on the thermal storage wattmeter is now entirely coincident with the curve of the thermal ammeter that was given at that time.

All of the data which have been presented to indicate the differences of indication between the thermal type of demand meter and other types of demand meters are based upon single customer loads. It is, of course, academically interesting to know what these variations are, but no account in this discussion has been taken whatever of the diversity factor. Mr. Ferguson in a paper presented before the Association of Edison Illuminating Companies many years ago stated that the diversity factor was one of the prerogatives of the central station, one of its inalienable rights. In other words, a high diversity factor assists the central station in all of its work and in its rate making.

Therefore, in the discussion of the application of metering devices to actual problems, it is essential to consider the diversity factor as paramount. When so considered, it will be found invariably that any academic differences of individual customer loads are gradually widened out, and that the general effect is the bringing together of the characteristics of various types of meters. 
In this connection I believe it would be very interesting to have at some later time a discussion of the measurement of actual load conditions when metered by the various types of demand meters operating upon various characteristic loads.

F. V. Magalhaes: It would be interesting to know what the performance of the instrument would be under varying external temperature conditions. Mr. Lincoln dismisses this point with the statement that the operating shaft will not turn with changes in external temperature. There are no actual figures given showing the temperature coefficient of the instrument.

He compares the results obtained by his instrument with one type of commonly used demand meter only and ignores entirely other types of demand meters and in particular one which has been available and in successful operation for several years. I refer to what is known as the Ingalls device. The indications obtained by the Ingalls device permit the demand to be calculated readily and accurately to any minute, and do not confine the demand to predetermined clock intervals.

Mr. Lincoln's comparison between the performance of his instrument and what he calls the Block-interval-type meter is entirely unfair to the Block-interval-type meter, as he shows absolutely no results obtained from the instrument itself on an actual test, but merely states its theoretical or calculated performance on an assumed load. He certainly is well aware that no load in practise follows cyclically the set intervals which can be imposed on a test load. It is a matter of record, as demonstrated by tests extending over long periods, that the blockinterval-type meter indicates the actual maximum demand of the circuit to within the instrument's error of registration. It is possible to impose on this type of instrument a short test run with a load definitely controlled within certain time limits, so that the instrument, although it will show with accuracy the maximum demand within its rated interval, will not show the highest figure that may have occurred in the short test period. This is by no means the fair or proper way to test such an instrument, and misleading conclusions should not be drawn from narrow test results so obtained.

Mr. Lincoln is very strongly in favor of standardizing the maximum demand interval for the entire country. This is a laudable desire, but it is very much of a question as to whether his desires in the matter are not colored more by the fact that his instrument is inherently a half-hour instrument rather than by a desire to settle the maximum demand troubles for the entire industry. Mr. Lincoln had some years' experience at Niagara Falls and is undoubtedly familiar with the one-minute and other special maximum demand periods which have in the past and still continue to be effective in that district.

There are other localities where contracts embodying a demand period of one hour have been in effect for years. It is possible to find still other localities where the demand period 
may be anything between one minute and one hour and the period justified by local conditions which could not be altered merely by a desire to standardize to some other period.

G. L. Hoxie: On the first page of Mr. Lincoln's paper he gave the reason for the maximum demand indicator, as follows: "The incorporation of maximum demand in a rate for electric service is an attempt to assess upon the user of that service hi:: proper share of the annual cost of equipment necessary for giving the service."

Now, it seems to be assumed in this paper that the annual cost of the equipment necessary to give the service which a customer uses is a function of the heating of that equipment due to such service. The limiting thing, however, may well be the maximum peak capacity of the generating stations of the company furnishing the current. It is only rarely that maximum possibility of service is determined by the capacity of equipment located outside of the generating or sub-stations. The maximum peak capacity of a generating station is not usually limited by heating. I believe in the case of a modern turbine that the number of kilowatts you can take out depends to a greater extent upon the steam end than upon the electric end, and a similar situation exists with many water power units, not with all, of course.

However, the principal comment, I wish to make is along the line of that of a previous speaker, and is in connection with diversity. Mr. Lincoln has used a very striking illustration of a customer taking one thousand kilowatt hours per year, and, if the service all be taken in one day, he takes current at 365 times the rate, as if his use were spread out over the year, and the inference is that his use of the company's apparatus costs the company 365 times as much as if the service were so spread out.

To carry that same illustration further, let us assume that there are 364 other customers, each taking current on a different day. In that case, so far as the production of the electricity is concerned, there would be no difference between the load of the 365 customers, each taking current on a different day, and one customer taking the same current every day.

It seems to be assumed in the paper that the heating effect shown by the customer's maximum demand meter, taken by itself, is the quantity which should be considered, but as a matter of fact, it seems to me it is the effect upon the generating stations of the company, due to this particular customer's draft of energy, combined as it is with the demands of all the other customers of the company; in other words, the customer's maximum demand, in itself, is not a question with which the generating company is necessarily concerned. The maximum demand of a particular customer which occurs synchronously with the maximum demand upon the generating stations, is the one thing which, it seems to me, must be considered, and therefore I would suggest modifying clause No. 2 in Mr. Lincoln's summary so that it will read: 
2. The cost of the necessary equipment to a given customer depends upon his demand coincident with the station maximum demand and not on his kilowatt hours of consumption.

That of itself eliminates the use of the one-minute peak for the ordinary customer. The one-minute peak of the ordinary customer will be smoothed out long before it reaches the generating station. In the case of a customer like a railway company, which may have a demand which is a large percentage of the total demand of the company, possibly a one minute peak may be an important quantity.

W. H. Pratt: There is a question I would like to ask, suggested by the sentence, "On the other hand, the thermal storage meter is perfectly definite in its indication. Each time a given load of given time duration is applied to this type of meter, it gives the same indication." What would be the comparative reading of two instruments, of different capacities, when put on the same load, for instance, an instrument of $1000 \mathrm{kw}$., and another one of $2000 \mathrm{kw}$., given a load of, roughly, say $900 \mathrm{kw}$., or $800 \mathrm{kw}$. It is, of course, necessary at times to use a device such as is available, but that might not be the device chosen were all capacities available.

It seems to me that there is no serious objection to using the logarithmic law of performance of demand meters for considerable classes of work. It seems to me also that it is a mistake to make a virtue of this logarithmic law, to place a special emphasis upon it, unless the law is pretty closely followed, and I judge from the figures given in this paper that it is not, in fact, that the departure is wide.

M. G. Lloyd: The objection which the author has spoken of to this meter in regard to the differences in registration with increasing loads and decreasing loads would not, on the face of it, be any objection if the load under consideration were the only load on the generating station. The fact that this meter very closely reproduces, in the effects within it, what is taking place in the generating apparatus, as regards heating, would make that matter take care of itself. However, in the case of a central station utility, one does not usually have a condition of that kind. The load of a particular customer is simply imposed upon a comparatively large load in the generator, in which case the effect is not reproduced in the generator, and consequently there is some objection to that characteristic in the meter.

Another factor which is to be considered and to which the author has referred, is the time taken for a generator or other apparatus to reach its final temperature, unless his assumptions are that one is starting from a condition of no load, and of course that does not apply to any particular customer's load being thrown on the line; and it is for that reason I think, that the central station does find it important to consider comparatively brief intervals of demand rather than demand covering periods of a half hour or longer. 
I should like to ask the author whether this instrument was made up in a form to be indicating rather than recording, in the sense of giving a graphic record.

A. S. Albright: We have had the opportunity of making some tests on the indicating form of the type " $\mathrm{RH}$ " meter. After various laboratory tests, the "RH" meter was installed on a typical factory load, together with two other demand meters, both of the graphic integrating type, and readings of the three meters were observed weekly for several months. The curves obtained, given in Fig. 1, show the comparative performance of the two types of meters on this installation. The thermal meter shows a higher demand in all cases. The break in the curves is caused by skipped readings.

We have had no experience with the graphic form of $\mathrm{Mr}$. Lincoln's meter.

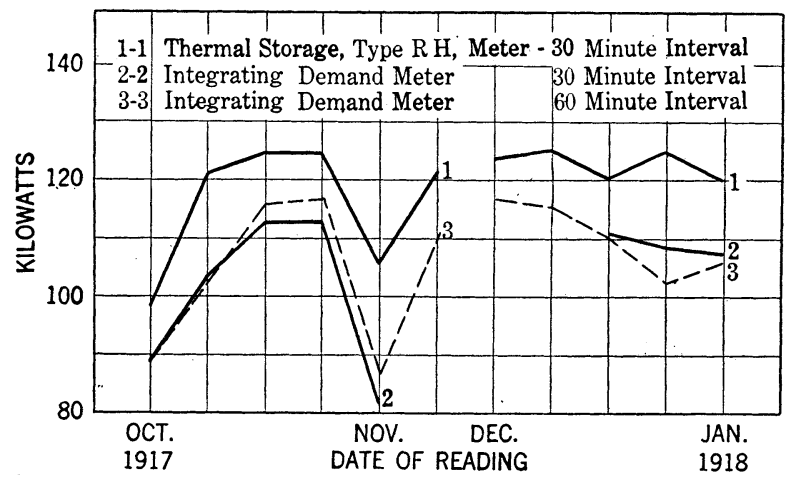

Fig. 1-Comparison of "Thermal Storage" with INTEgrating Demand Meters on a Typical Factory Load

H. D. James: There is another use for this thermal storage meter which I wish to bring out, because I believe it has an important field, and that is in connection with individual pieces of apparatus. I have particularly in mind the motor. Many motors are operated on an intermittent load. The operator is, in many cases, desirous of knowing what is the average heating effect of this load on the motor. If he has an ammeter in front of him, and it varies back and forth, he must make a mental integration of the heat. If, however, we place a time-demandoverload meter on the motor, he does not know what is going to happen until the motor shuts down. If, however, he has a meter which indicates the heat going into the motor-a 30-minute time interval is long enough for most applications-he will have in front of him an ammeter which is giving him a true integration of the heat in his motor, and continually indicating what is going on, and when the needle reaches a predetermined point 
his motor will shut down, and stay shut down a predetermined time, before he can start it up again.

Such a device is very desirable, and I think it is one of the devices the trade has been working toward for a number of years. We have the thermo-couple in the large generator, but so far it does not seem as though the thermal couple for the small apparatus can be produced commercially. We have a time-element-overload relay, which is commercial, but it has only a short time interval.

If we have a thermal integrating meter which is useful for not only determining the charge the customer should pay for the power he consumes, but also as a protection for his motor, and which will allow the customer to operate the motor close to its maximum, and still keep within the proper heat limit.

H. L. Wallau (by letter): The thermal type of demand meter is sure to have a promising future, once its operating characteristics are thoroughly understood.

Its simplicity, reliability, absence of clock troubles, coupled with the fact that on a load of given characteristics it will always duplicate its previous indications, are valuable assets. This was shown by test, and it was also found to be very accurate with variable voltage and at various power factors.

Where a number of such meters are connected in series with a load all should give the same indication. To my knowledge, this is the only meter possessing this very desirable characteristic. Lack of synchronism in clock movements prevents similar results from being obtained with the usual types of demand meters now available. This last feature we have been as yet unable to check by tests because we had but one meter available for testing purposes.

Its accuracy depends upon the brightness of the nickel plated heater casings remaining unimpaired. Just what effect the exposure of this type of meter to fumes and gases in industrial establishments will have, remains to be seen.

The author has discussed its principles, acknowledges that on heavy loads of relatively short duration its registration is above the arithmetical mean, but points out that it does truly follow the heating characteristics of the energy supply devices and therefore that this is a point in its favor.

It is self-evident that if every consumer of a class pays his just share of the cost of delivering current to him, there will be no discrimination in favor of any, and that the ultimate effect must be to allow of rate reductions to the class, as a whole, more rapidly than if some losses must be absorbed due to inequalities in charges favoring short-hour users. Commercial expediency may modify the application of this principle somewhat, but its truth remains unchanged.

As regards the period during which the maximum demand should be measured, considerable difference of opinion is yet manifest. One large company uses an hour period and reads 
the demand weekly. The average of the four readings is billed as the monthly demand. The object of this is to prevent the undue penalization of a consumer for some abnormal demand which might accidentally be made on a certain day, and which is not typical of the general operating characteristics of his load.

In my judgment the meter with a time period, such that 90 per cent of the load will be indicated in the interval for which the demand is taken under the contract, is preferable to that in which only 63.2 per cent of the load would be indicated in that period.

P. M. Lincoln: Mr. Hall refers to the thermal capacity of the equipment, and states that on the basis of thermal capacity that the meter used should be a current meter, an ammeter rather than a wattmeter. That is true within limits. It is not true that apparatus in general has a temperature in proportion to the amperes carried. If all of the heat were due to the passage of the current, that statement would be true, but in electrical apparatus in general, only a part of the heat is due to the passage of the current.

In large turbo-alternators, the armature copper loss amounts to only 10 or 20 per cent of the total, and consequently the heating of that device is not proportioned, by any means, to its ampere capacity. The same is true of other pieces of electrical apparatus which are used, even the cable. The heating of cables depends almost wholly, to be sure, on the current carried, but the next paper indicates that a considerable proportion of the losses which take place in cables is due to the element depending on the voltage, so that an element which depends on current alone is not sufficient to insure the heating of electrical apparatus in general. It must be something which takes in elements other than mere amperes.

I maintain, therefore; that the wattmeter will probably in general come nearer measuring the true capacity of the apparatus than will an ammeter, although the ammeter on exactly the same principles is available, and will undoubtedly have a considerable part in the future of demands as they are measured.

Another thing called attention to is this matter of the time of diffusion, the time it takes for heat to diffuse through the meter element. Mr. Hall's view of that feature and mine seem to be different. I consider the time of diffusion as a distinct handicap. I think that Mr. Hall considers it an advantage, and there is a distinct difference of opinion between us on that particular point. I wish I could produce a device in which the time of diffusion was zero.

It was found that a true logarithmic law would avoid the error shown in Fig. 16 of my paper. It is the time taken for the diffusion of the heat throughout the meter limit which gives rise to departure from the true logarithmic law, and therefore gives rise, in the case of the thermal meter, for analyzing the true logarithmic average as analyzed in Fig. 16. 
I wish it were possible, therefore, to avoid the time of diffusion throughout the meter element. I consider that time of diffusion as a distinct disadvantage. Possibly as things go along, we will find means of overcoming it.

Mr. Magalhaes asks concerning the temperature coefficient of the meter. I have made a good many measurements of the temperature coefficient, and the temperature error is so small that it is pretty hard to make an accurate determination of it. In general, I can say that it is about one-tenth or one twentieth of a per cent for each degree of change in centigrade temperature. That is not a very large change, but as I say, it is a difficult thing to measure because it is so small.

Mr. Magalhaes speaks of a device which he calls the Ingalls device. I am not prepared to comment on that, because I am not familiar with the device he mentions.

Mr. Hoxie and several other gentlemen have objected to my conclusions, in that I have taken the cost of the customer's equipment as being proportional to the maximum demand of that customer. Mr. Hoxie and the others who referred to that point spoke specifically of the generator capacity, and if we consider generator capacity only, they are more or less correct in their conclusions. However, it is true that the majority of the cost of electrical equipment for serving the customers is not in the power house. It is out on the line. I think if the cost of equipment for serving customers is analyzed they will find that the cost of equipment at the customers' end amounts to a good many times the cost of equipment in the generating station, and the cost of the equipment at the customer's premises is something that depends on the customer's demand. The diversity factor takes care of that if it goes back into the system, and it is true, as pointed out, that the maximum demand of the customer does not affect the generating capacity to anything like the same extent that it affects the apparatus which is placed at the premises of the customer.

You must remember in this connection that the customers are very many, and that the separate pieces of apparatus to serve them run into thousands of pieces, and the aggregate cost of these pieces in general is considerably higher than the cost of the generating equipment to serve these customers. That consideration, therefore, leads me to quite a different conclusion than if one is considering the generating equipment only.

Mr. Hoxie spoke of my illustration of the customer who insisted on taking his entire year's supply in a single day, and said that if there were three hundred and sixty-five customers, each of whom took his load on one day of the year, that my illustration would not apply, but my illustration does apply, because each of these customers would have to have equipment enough to take care of the whole output of the generating station during that day, which would be practically as much equipment as there is in the generating station, and it would mean practically 
multiplying the equipment of the customer by 365 , which would certainly be a large increase in the total cost of power for that station. I cannot agree with Mr. Hoxie on that point.

Mr. Pratt asked concerning the difference in indication, for instance, of a 1000-watt wattmeter as compared to that of a 2000-watt wattmeter. There is no difference. It does not matter what the capacity is, a 2000 -watt wattmeter will indicate the load as much as a 1000-watt wattmeter. There is a difference, however, in the indication of two different times. If we had a 30-watt wattmeter, and compared that with the indications of our demand wattmeter, the indications of these two would not necessarily be the same, and would depend on the character of the load. If the loads are the same, they would give the same results. If the load had high peaks, the meter with the short time element would give higher indications than the one with the longer time element. That depends on the application of a logarithmic law.

Mr. Albright speaks of a number of tests made in Detroit of this device, and states that the indication of the 30-minute thermal demand, as compared with meters of the same kind, and as compared with meters of a different type, taken through a number of weeks, shows that the thermal meter gives a higher demand in all cases, and that is about what one would expect, and would indicate that the particular load he has it on is not a steady load, but one with a number of peaks in it. As I recall it, he applied it to a machine shop load in which the peaks are rather marked, and it was only to be expected that the thermal demand meter would give higher results in the case of such a load than the wattmeter.

Concerning the application of a device of this kind as a motor protection, as spoken of by $\mathrm{Mr}$. James and Mr. Atkinson, that is an entirely practical application, and I look for that application to be developed to a considerable extent in the future. 